(C) The Authors 2013 First published online 11 September 2013

The Nutrition Society Irish Section 22nd Annual Postgraduate Meeting was hosted by Queen's University Belfast on 14-15 February 2013

\title{
The potential role of fruit and vegetables in aspects of psychological well-being: a review of the literature and future directions
}

\author{
Ciara Rooney*, Michelle C. McKinley and Jayne V. Woodside \\ Nutrition and Metabolism Research Group, Centre for Public Health, Queen's University Belfast, Belfast BT12 6BJ, UK
}

\begin{abstract}
The objective of the present paper was to review the literature investigating the potential relationship between fruit and vegetables (FV) and psychological well-being. The rising prevalence of mental ill health is causing considerable societal burden. Inexpensive and effective strategies are therefore required to improve the psychological well-being of the population, and to reduce the negative impact of mental health problems. A growing body of literature suggests that dietary intake may have the potential to influence psychological well-being. For example, studies have suggested that particular dietary constituents, including vitamins and minerals, might be beneficial to psychological health. However, in order to better reflect normal dietary intake, health-based research has increasingly begun to focus on whole foods and dietary patterns, rather than individual nutrients. One food group that has received increasing attention with regard to psychological health is FV. This is probably a result of the strong evidence base, which exists in relation to their protective association with a number of chronic diseases, as well as the fact that they are a rich source of some of the nutrients which have been linked to psychological health. While some promising findings exist with regards to FV intake and psychological well-being, overall, results are inconsistent. Possible reasons for this, such as methodological issues related to study design and the measurement of psychological well-being and FV intake, are discussed within this review. Based on the predominantly observational nature of existing literature, the present paper concludes that future well-designed randomised controlled trials are required to investigate the relationship further.
\end{abstract}

Nutrition: Fruit and vegetables: Psychological well-being

Mental health is an integral component of overall health and well-being ${ }^{(1)}$. Despite this, there is growing international concern about the rising prevalence of mental ill health. Conservative estimates suggest that within Europe alone, $38 \cdot 2 \%$ of the total population suffer from mental health disorders annually ${ }^{(2)}$. Currently ranked as the third leading cause of burden of disease worldwide, and set to become the principal cause by 2030, it is evident that poor mental health is having a profound impact in terms of societal burden ${ }^{(3)}$. Mental ill health has the potential not only to impact upon the day-to-day functioning and well-being of the suffering individual $^{(4)}$, but is also closely linked with an elevated risk of, and even mortality from, certain physiological illnesses including CVD, stroke and some cancers ${ }^{(1,5)}$. Furthermore, the economic cost associated with poor mental health is vast, contributing to approximately 798 billion $€$ in Europe alone ${ }^{(6)}$. Thus, based on the prevalence and negative impact of mental ill health, there is a compelling need for inexpensive and effective strategies to improve the psychological well-being of the population, and to reduce the risk and burden of mental health problems.

The factors involved in psychological health are multifaceted, comprising not only genetics, but also several biological and environmental factors. Hence, researchers

Abbreviations: CS, cross-sectional; FV, fruit and vegetables; PD, psychological distress. *Corresponding author: C. Rooney, fax +44 (0)2890235900, email crooney37@qub.ac.uk 
have begun to examine the potential influence of lifestyle factors on psychological well-being. For example, a host of studies exist to support the beneficial role of physical activity on aspects of psychological well-being including general mental health, quality of life and depression ${ }^{(7,8)}$. Conversely, although dietary intake, an equally important lifestyle factor, has been studied extensively in relation to physical health, it is only in more recent years that evidence has begun to emerge on its potential role in psychological health. Interest in the area was partly initiated by early studies, which linked certain nutritional deficiencies with psychological conditions ${ }^{(9)}$. For instance, sub-optimal levels of B vitamins have been associated with mental health complaints including depressed mood ${ }^{(10)}$. Naturally, such discoveries provoked several investigations into how individual nutrients could influence psychological well-being. However, in order to better reflect typical dietary intake, whereby nutrients are rarely consumed in isolation, the focus of many recent studies has moved towards examining whole foods and dietary patterns in relation to improving psychological well-being ${ }^{(11)}$.

One food group which has received increasing attention in this regard is fruit and vegetables (FV). It is widely accepted that FV are an important component of a healthy lifestyle, with the WHO and FAO advocating a minimum daily intake of $400 \mathrm{~g}$ or five portions ${ }^{(12)}$. This is primarily due to the abundance of literature, which shows that FV may play a central role in the prevention of some physiological diseases including CVD, certain cancers and diabetes ${ }^{(13,14)}$. Perhaps unsurprisingly, the strong evidence base for the physiological health benefits of FV have led academics to question these foods capability to impact upon aspects of positive (e.g. happiness and vitality) and negative (e.g. depression and anxiety) psychological health. Another likely reason for the interest is that FV are a rich source of many nutrients, each with an array of biological mechanisms, which could justifiably impact on psychological functioning.

This review will first provide an insight into the possible mechanisms linking FV and psychological wellbeing, before examining current literature on the area within the general population. It will discuss key methodological issues among existing studies. While cognition is a pertinent factor in psychological health, it is not discussed within the current review.

\section{How might fruit and vegetables and psychological well-being be linked? Possible causal mechanisms}

Although the mechanisms of action linking FV intake and psychological health remain to be clarified, a number of speculative concepts have been proposed. The majority of these are centred on the ability of certain nutrients contained within FV to influence psychological well-being. While a number of nutrients such as $n-3$ PUFA ${ }^{(15)}$, vitamin $\mathrm{B}_{12}{ }^{(10)}$ and vitamin $\mathrm{D}^{(16)}$ have been studied with regard to psychological well-being, this review only focuses on nutrients that are found in FV, and which have shown promise in this regard.

\section{Complex carbohydrate content}

Carbohydrates have been studied extensively in relation to psychological functioning, and in particular mood. The proposed link is that insulin, triggered through the consumption of carbohydrates, can increase entry of tryptophan in the brain, which in turn stimulates the synthesis of important neurotransmitters including serotonin $^{(9)}$. Although evidence has indicated that the ingestion of simple carbohydrates, present in refined sugary products, may result in temporal improvements in mood $^{(17)}$, it has been suggested that complex carbohydrates provide a longer lasting effect due to their slower release of glucose ${ }^{(18,19)}$. Complex carbohydrates are particularly prevalent in low glycaemic index foods including certain types of FV (e.g. beans, peas and bananas), and thus this is a potential mechanism put forward for the hypothesised role of FV in psychological well-being.

\section{$B$ vitamin content}

FV are rich sources of B vitamins, in particular folate (e.g. spinach, Brussels sprouts and oranges) and vitamin $\mathrm{B}_{6}$ (e.g. peas and bananas) ${ }^{(20)}$. There are two key mechanisms proposed for their relationship with psychological functioning. The first relates to their effect on singlecarbon metabolism, which can impact upon the synthesis of important neurotransmitters including serotonin, other monoamine transmitters and catecholamines ${ }^{(21)}$. The second is in connection with their role in the conversion of homocysteine to methionine, which is a precursor of S-adenosylmethionine, and essential for methylation processes in the brain $^{(22)}$. Deficiencies in these nutrients can therefore result in elevated homocysteine levels, and reduced synthesis of neurotransmitters, which may provoke psychological changes including depressed $\operatorname{mood}^{(23)}$.

Some promising research exists to support the relationship between B vitamins and psychological health ${ }^{(24,25)}$. A recent systematic review ${ }^{(25)}$ that looked at eight randomised, placebo-controlled trials concluded that supplementation with B vitamins (particularly at high doses) may have beneficial effects in terms of reducing stress, mild psychiatric symptoms and anxiety in healthy populations. Nevertheless, the relationship remains ambiguous, with two additional systematic reviews ${ }^{(26,27)}$ highlighting conflicting findings and a lack of conclusive evidence between folate, folic acid and vitamin $\mathrm{B}_{6}$ and depression within cross-sectional (CS) and experimental studies, respectively. However, discrepancies between systematic reviews may at least be partly explained by differences in the specific objectives and focus of each review (e.g. inclusion of certain study types or focus on particular psychological outcomes or diet $v$. supplements). Despite the equivocal findings to date, $\mathrm{B}$ vitamins present another promising link between FV and psychological well-being.

\section{Antioxidant content}

Vitamins $\mathrm{C}$ and $\mathrm{E}$, as well as phytochemicals including polyphenols, which are present in $\mathrm{FV}$, have 
also received attention in relation to psychological health. A prevailing theory is that the antioxidant properties of these nutrients can act as a defence mechanism against oxidative stress, which can be detrimental to mental health ${ }^{(28)}$. Antioxidants in FV may also be beneficial towards lowering inflammatory markers, which have been implicated in the onset of poor mental health including depression ${ }^{(29)}$.

Although the relationship between antioxidant nutrients and psychological health is currently ambivalent, with some studies refuting the hypothesis ${ }^{(30-32)}$, a number of studies have provided evidence to support the link. For example, one CS study ${ }^{(29)}$ demonstrated associations between the dietary intake of antioxidants and depressed mood in older adults, whereas another showed that concentrations of plasma carotenoids were associated with optimism $^{(33)}$. Furthermore, vitamin $\mathrm{C}$ has been shown in a systematic review ${ }^{(26)}$ to be potentially beneficial towards depressive symptoms in non-clinically depressed individuals, although the authors acknowledge that this conclusion was based on limited evidence. Consistent with this, other single ${ }^{(34)}$ and multi-vitamin/mineral trials ${ }^{(21)}$ have shown inverse associations between vitamin $\mathrm{C}$ and psychological outcomes including mood, confusion and personal strain. Similarly, two CS studies $^{(35,36)}$ found plasma levels, and dietary intake of vitamin $\mathrm{E}$, to be associated with better mental health and reduced odds of depression in elderly populations. Evidence is also accumulating on the role of certain phytochemicals, including polyphenols, in influencing aspects of psychological health ${ }^{(37)}$. Studies to date have suggested that these phytochemicals might have mood altering effects, in animal ${ }^{(38)}$ and in human populations ${ }^{(39,40)}$. Taken together, given that FV are an abundant source of antioxidants, this evidence lends further reasoning to researching the capacity of $\mathrm{FV}$ to affect psychological health.

\section{Mineral content}

Certain minerals contained within FV have also been shown to have important functions in the brain ${ }^{(41)}$, and hence have been linked to improvements in psychological health, including iron ${ }^{(42)}$, calcium and magnesium ${ }^{(43)}$.

\section{Brain-derived neurotrophic factor}

In comparison with high saturated fat and refined sugar diets, FV-rich diets are thought to be conducive to increasing levels of brain-derived neurotrophic factor ${ }^{(44)}$, which is an important protein required for several brain functions including neural development and synoptic plasticity in neurons ${ }^{(37)}$. Lower levels are therefore thought to contribute towards poor psychological health including depression.

\section{People's perceptions of fruit and vegetables}

Finally, it is possible that a person's perception of how 'healthy' a food is can impact upon their subsequent psychological well-being. Some research has shown that the consumption of healthy food choices, which are perceived to be lower in calories can provoke positive emotions $^{(45,46)}$. Hence, as FV are generally deemed as healthy, their intake might lead to both the expectancy of psychological benefits and subsequent improvements in psychological well-being.

\section{Fruit and vegetables and psychological well-being: existing research evidence}

An overview of existing evidence on FV and psychological health outcomes is discussed in the following sections.

\section{Observational evidence: cross-sectional studies}

Evidence to date on FV and psychological well-being is largely observational in nature, with most studies having employed a CS design. Table 1 shows examples of themost relevant observational studies (the larger studies that focused on FV specifically rather than FV-rich diets). The psychological outcome that has received the most attention with regard to FV consumption to date is depression. This is perhaps not surprising given the mood-altering evidence from the aforementioned individual nutrient studies. However, overall results to date are equivocal. A recent systematic review ${ }^{(27)}$, for example, found discordant results among CS studies that examined FV in relation to depression. Out of the four FV-based studies that were included in the review, one reported a significant inverse association ${ }^{(57)}$, two did not demonstrate any association ${ }^{(50,61)}$, and the remaining article reported that depressive symptoms were related to vegetable intake but not fruit intake ${ }^{(62)}$. This inconsistency is also evident over a number of additional CS studies. For example, a recent repeated (five time points between 2000 and 2009) CS study ${ }^{(28)}$ of Canadians produced a pooled estimate across all time points, which showed that greater FV consumption was significantly associated with a $27 \%$ reduced odds of depression. Encompassing 296121 individuals, this study is currently the largest conducted to date on the area of FV and psychological well-being. Interestingly, when FV were examined separately, associations with depression were found to be similar. The authors therefore suggested that the beneficial effects of FV on mental health may be due to the adoption of dietary patterns characterised by FV intake, rather than the mechanisms provided by individual nutrients contained within different types of FV. However, the study did not control for other dietary components and hence it was not possible to examine if other foods contributed to the associations reported. Notably, the study also showed inverse associations between FV intake and other psychological outcomes at most time points, including psychological distress (PD), the presence of mood and anxiety disorders and self-perceived poor mental health status. Further epidemiological studies have also supported the hypothesis that FV consumption is associated with depressed $\operatorname{mood}^{(63,64)}$. Likewise, studies have demonstrated that the adoption of optimal healthy lifestyle behaviours, adherence to nutritional guidelines and good diet quality (all involving eating adequate amounts of FV) is 
Table 1. Overview of some existing observational studies examining fruit and vegetable intake in relation to the most commonly researched psychological outcomes

\begin{tabular}{|c|c|c|c|c|c|c|c|c|}
\hline \multirow[b]{2}{*}{ Ref } & \multirow{2}{*}{$\begin{array}{l}\text { Study } \\
\text { design }\end{array}$} & \multicolumn{2}{|r|}{ Participants } & \multirow[b]{2}{*}{ Outcome } & \multirow[b]{2}{*}{ Exposure } & \multicolumn{3}{|c|}{ Association? } \\
\hline & & $n$ & Characteristics & & & Yes & No & Mixed $^{*}$ \\
\hline (28) & CS & 296121 & General population (MF) & Depression & FV & & & $\checkmark$ \\
\hline (47) & CS & 38759 & College students (MF) & Depression & FV & & & $\checkmark$ \\
\hline (48) & CS & 10602 & General population (M) & Depression & FV & & & $\checkmark$ \\
\hline (49) & CS & 5529 & University students (MF) & Depression & FV & & & $\checkmark$ \\
\hline (50) & CS & 4734 & School students (MF) & Depression & $\mathrm{FV}$ & & $\checkmark$ & \\
\hline (47) & CS & 38759 & College students (MF) & $\mathrm{MH}$ & FV & & & $\checkmark$ \\
\hline (51) & CS & 16792 & General population (MF) & $\mathrm{MH}$ & FV & & & $\checkmark$ \\
\hline (52) & $\mathrm{PC}$ & 11377 & General population (MF) & $\mathrm{MH}$ & FV & & & $\checkmark$ \\
\hline (28) & CS & 296121 & General population (MF) & PD & FV & & & $\checkmark$ \\
\hline (53) & CS & 52600 & Older adults (MF) & PD & FV & $\checkmark$ & & \\
\hline (54) & CS & 6587 & $\begin{array}{l}\text { Whites, Hispanics, } \\
\text { African Americans (MF) }\end{array}$ & PD & FV & & & $\checkmark$ \\
\hline (28) & CS & 296121 & General population (MF) & Anxiety & $\mathrm{FV}$ & & & $\checkmark$ \\
\hline (55) & CS & 853 & General population (MF) & Anxiety & FV & & $\checkmark$ & \\
\hline (56) & CS & 34603 & Employees (MF) & Stress & FV & & $\checkmark$ & \\
\hline (57) & CS & 2541 & College students (MF) & Stress & Fruit & $\checkmark$ & & \\
\hline (58) & CS & 1839 & University students (MF) & Stress & FV & & & $\checkmark$ \\
\hline (59) & CS & 80000 & General population (MF) & Mood/affect & FV & $\checkmark$ & & \\
\hline (60) & CS \& L & 281 & Young adults (MF) & Mood/affect & FV & & & $\checkmark$ \\
\hline
\end{tabular}

Ref, reference; CS, cross-sectional; MF, males and females; FV, fruit and vegetables; M, males; MH, mental health; PC, prospective cohort; PD, psychological distress; L, longitudinal.

*Significant associations were detected for certain subsets of participants e.g. males/females, types of FV or particular subscales of questionnaires, but not for others.

associated with a reduced risk of depression or depressive symptoms ${ }^{(56,65,66)}$. Moreover, certain dietary patterns characterised by high intakes of FV, have been associated with a decreased prevalence of depression ${ }^{(67,68)}$.

However, despite these positive findings, some studies have failed to produce evidence to support an association between either FV intake ${ }^{(69)}$ or FV-rich dietary patterns $^{(70)}$ and depression. In fact, the majority of existing studies have reported heterogeneous results, either with regard to specific subsets of participants or types of FV. For example, some studies found FV was associated with depression in females but not in males ${ }^{(49,58)}$, whereas one ${ }^{(47)}$ reported the opposite. These findings could be explained in part by evidence that shows that females are more likely to be aware of healthy eating guidelines, and to report healthy eating behaviours, including consuming $\mathrm{FV}$, than their male counterparts ${ }^{(71)}$. In addition, some studies found depression was associated with some varieties of FV but not with others ${ }^{(48,62,70,72)}$. A possible reason for this is that different varieties of FV have different nutritional compositions and hence may not be linked with psychological outcomes to the same extent. Alternatively, as these are findings from CS studies, the possibility that an individual's mood may impact upon their subsequent choice of FV cannot be ruled out ${ }^{(73)}$.

Studies have also investigated the association between FV intake and general mental health. For example, Eckert et $a l^{(74)}$ reported that among 2545 Australian adults, eating one serving or less of vegetables daily was a predictor of mental illness. Similarly, an inverse association has been found between a worse diet score (including low FV consumption) and increased mentally unhealthy days ${ }^{(75)}$, and a positive relationship has been shown between a higher Mediterranean diet score and mental health ${ }^{(76)}$. Interestingly, further studies have reported positive relationships between FV intake and general mental health, but similar to before, with inconsistent results for males and females ${ }^{(51,77)}$. Additionally, a study by Adams and Colner ${ }^{(47)}$ reported differing results not only between genders, but also according to subscales assessed under the term mental health. Among females, FV intake was associated with feeling hopeless and overwhelmed, but not with feeling exhausted, very sad, or depressed, or being diagnosed with depression. Hence, evidence to date on FV intake and general mental health is inconsistent.

Investigations have also been conducted on the relationship between FV and PD, stress, anxiety and general mood. Some have reported inverse associations between FV consumption and $\mathrm{PD}^{(28,53)}$ whereas others have illustrated heterogeneous results between genders ${ }^{(78)}$ and race ${ }^{(54)}$. Kiviniemi et al. ${ }^{(54)}$ found that higher levels of PD were associated with lower FV consumption in their overall sample ( $n$ 6587), and among White persons and Hispanics, but not in African Americans. The authors speculated that this was possibly because of racial variations in food selection when experiencing negative moods. Similarly, studies examining stress and anxiety have produced inconclusive findings, with some showing inverse associations ${ }^{(57)}$, some finding none $(55,56,69)$ and others reporting heterogeneous findings based on gender ${ }^{(58)}$ and time points of a repeated CS study $^{(28)}$. Researchers have also looked at the potential association between FV and general mood. For example, a recent study ${ }^{(6)}$ found that higher positive effect was associated with consuming 0.112 more servings of fruit 
and 0.147 more servings of vegetables among a sample of young adults. However, FV consumption was not significantly associated with negative affect. The researchers suggested that seven to eight servings of FV may be required to experience changes in positive effect. In line with this, another recent study ${ }^{(59)}$ that used three large datasets comprising approximately 80000 British individuals, found that FV intake was associated with seven areas of psychological well-being including life satisfaction, mental well-being, mental disorders, selfreported health, happiness, nervousness and feeling low. Similar to the previous study, the authors concluded that well-being peaks at approximately seven portions of FV per day. Such details on the portions of FV associated with psychological benefits are unique among existing research, and would be a useful addition to future studies.

To a much lesser extent, some CS studies have also shown that FV consumption is associated with more positive aspects of psychological well-being including happiness $^{(79)}$, life satisfaction ${ }^{(80,81)}$, optimism ${ }^{(82)}$ and selfesteem $^{(83)}$. However, as with all of the studies discussed within this section, it is not possible to determine the causal nature of these relationships because of their correlational study designs.

\section{Observational evidence: longitudinal studies}

Evidence in the form of longitudinal studies is limited in relation to FV and psychological well-being. With regard to depression, based on evidence from two longitudinal studies ${ }^{(20,84)}$ a recent systematic review ${ }^{(24)}$ concluded that an FV-rich diet may be protective against depression. In line with this, a study of 12404 participants showed that a traditional diet (characterised by fish and fruit consumption) and a healthy pattern (characterised by vegetable consumption) were both associated with lower odds of depression in females and males, respectively ${ }^{(85)}$. However, the results indicated that reverse causality may have existed in the case of the healthy pattern (i.e. more depressed males may have consumed less vegetables). Conversely, another study ${ }^{(86)}$ of 1609 older Taiwanese adults, observed that after adjustment for cognitive status, only vegetables were protective against depressive symptoms 4 years later.

In addition to depression, some longitudinal studies have also investigated the role of FV in relation to general mental health. For example, one study ${ }^{(52)}$ demonstrated that large improvements in diet (based on FV intake) over a 2-year period was associated with improved self-rated mental health. However, it is worth noting that this was only the case for those with the greatest improvement in their diet, and only applied to certain subscales ('peacefulness' and 'happiness') of mental health as measured by the SF-36 questionnaire. Similarly, another study showed that increased adherence to a Mediterranean type diet over 4 years was only significantly associated with increased vitality (and no other subscales of the SF-36) when compared with those who had decreased or maintained adherence. Healthy diets ${ }^{(87)} /$ good quality diets ${ }^{(8)}$ have also been associated with improvements in emotional functioning, mood and mental health among adolescents. However, this association was attenuated after adjustment for confounders in the latter study ${ }^{(88)}$. Interestingly, the authors suggest that the results of the former study ${ }^{(87)}$ do not support the hypothesis of reverse causality, as mental health at baseline did not predict diet quality at follow-up. Furthermore, a longitudinal study ${ }^{(89)}$ has shown that a high level of dispositional optimism was associated with greater FV intake. Finally, using lagged analyses, White et al. ${ }^{(60)}$ also found that positive affect (measured using daily diaries over $21 \mathrm{~d}$ ) was predicted by FV intake on the preceding day and not vice versa.

\section{Experimental evidence}

There is a paucity of experimental evidence investigating the effect of FV consumption on psychological wellbeing. Table 2 shows examples of the most relevant experimental studies (those which specifically examined the effect of FV intake on psychological outcomes). Of those studies that exist, the majority have (i) investigated the effect of FV on psychological well-being as a secondary outcome and (ii) investigated the effect of FV modification in conjunction with other dietary or lifestyle changes. Despite this, four dietary interventions have focused more specifically, or have carried out additional analysis, on FV and psychological health ${ }^{(92-95)}$. The majority of these have reported heterogeneous findings ${ }^{(92,93,95)}$. For example, Plaisted et al. ${ }^{(92)}$ found that although an FV-rich diet was associated with improved vitality in hypertensive participants over 11 weeks, there were no significant differences when compared with an FV-rich, low-fat dairy diet group or a control group. Furthermore, the FV-rich diet was not associated with any improvements in overall mental health. Another study ${ }^{(93)}$ examined the effect of two multi-component lifestyle interventions $v$. an advice only intervention on the health-related quality of life of pre-hypertensive/ stage one hypertensive participants over 18 months. The results showed that adherence to blood pressure control guidelines (including increased FV intake) and adherence to the same guidelines, plus a dietary approaches to stop hypertension diet, resulted in improvements in vitality, but not general mental health when compared with the advice only group. Furthermore, increased FV intake after 6 months was associated with increased vitality. However, no similar effects were detected for any other dimension of mental health as measured by the SF-36 questionnaire. In addition, the results for FV were not observed at the final follow-up visit (18 months). Similarly, Torres et al. ${ }^{(95)}$ showed that increased FV consumption during a mixed component dietary intervention (14 weeks) in postmenopausal women led to reduced confusion, but not any other elements of mood (using the Profile of Mood States questionnaire). Moreover, when the two intervention groups (lean meat and FV-rich diet $v$. reduced fat, wholegrain bread and cereals diet) within the study were compared, although both groups experienced improvements in mood, anger was the only variable found to be statistically different between them (reduced anger was found in the latter diet group). 
Table 2. Overview of some existing experimental studies examining the effect of fruit and vegetables on outcomes of psychological well-being

\begin{tabular}{|c|c|c|c|c|c|c|c|c|c|}
\hline Ref & $\begin{array}{l}\text { Study } \\
\text { design }\end{array}$ & \multicolumn{2}{|c|}{ Participants } & Intervention & Duration & Outcome & \multicolumn{3}{|c|}{ Effect? } \\
\hline (90) & $\mathrm{RCT}(\mathrm{DB})$ & Twelve & Memory decline (MF) & Concord grape juice v. placebo & 12 weeks & Depression & & $\checkmark$ & \\
\hline (92) & $\mathrm{RCT}$ & Eighty three & Hypertensive (MF) & $\begin{array}{l}\text { Control diet } v \text {. FV diet } v \text {. } \\
\text { Combination diet }\end{array}$ & 11 weeks & $\mathrm{MH}$ & & $\checkmark$ & \\
\hline (93) & RT & 762 & $\begin{array}{l}\text { Pre/stage } 1 \\
\text { hypertensive (MF) }\end{array}$ & $\begin{array}{l}\text { Advice only } v . \text { EST } v \text {. } \\
\text { EST and DASH }\end{array}$ & 18 months & $\mathrm{MH}$ & & & $\checkmark$ \\
\hline (95) & RPGT & Ninety five & Postmenopausal (F) & $\begin{array}{l}\text { Vitality diet (Lean meat, >FV) v. } \\
\text { Healthy diet (LF, > wholegrain } \\
\text { breads and cereals) }\end{array}$ & 14 weeks & Mood/affect & & & $\checkmark$ \\
\hline$(96)$ & RPGT (SB) & Twenty five & General population (F) & $\begin{array}{l}\text { No diet change } v \text {. diet change } \\
\text { (>FV, fish, nuts, seed, LF dairy } \\
\text { and wholegrain cereals) }\end{array}$ & $10 d$ & Mood/affect & & & $\checkmark$ \\
\hline
\end{tabular}

$\mathrm{RCT}$, randomised controlled trial; DB, double-blind; MF, males and females; I, intervention; FV, fruit and vegetables; MH, mental health; RT, randomised trial; EST, established guidelines for blood pressure control; DASH; Dietary Approaches to Stop Hypertension; RPGT, randomised parallel group trial; F, females; LF, low fat; SB, single-blind.

*Significant effects were detected at certain time points during the intervention, or for particular subscales of questionnaires, but not for others.

Finally, another study ${ }^{(94)}$ compared the effect of nutrition education $v$. behavioural counselling on FV intake and quality of life over the period of 1 year. Although FV intake and mental health scores increased in both groups, FV consumption was not found to be significantly associated with changes in mental health.

Intervention trials involving fruit juice consumption, for example cranberry juice ${ }^{(9)}$, concord grape juice ${ }^{(90)}$ and blueberry juice ${ }^{(91)}$ have also been published with regard to mood and depression, although no significant effects have been documented to date. One potential reason for this is the methodological limitations of existing studies including the lack of use of a validated outcome questionnaire ${ }^{(97)}$, small sample sizes and lack of randomisation $^{(91)}$.

Further experimental studies have looked at the effect of FV-rich dietary patterns on psychological outcomes. For example, two studies examined the effect of a Mediterranean diet on psychological health, with conflicting findings. One ${ }^{(98)}$ found no significant effects of a Mediterranean diet in comparison with a low-fat diet, or control diet, in terms of general mental health, mood, depression or stress over 12 weeks in 155 raised cholesterol participants. The second ${ }^{(96)}$ reported that there were significant differences between a Mediterranean and control diet in terms of their effect on vigour, alertness and contentedness in a random sample of twenty-five females over $11 \mathrm{~d}$, but not with regard to any other subscales of the outcome measurements used (Profile of Mood States and Bond-Lader Visual Analogue Scales). Similar heterogeneous findings for the effect of a vegetarian dietary intervention on depression, anxiety, stress and general mood have been found based on discordant results per subscale of the psychological measurement tool used ${ }^{(99)}$.

Other studies have been more varied in their approach, in that the interventions have targeted other lifestyle behaviours as well as FV intake, such as physical activity ${ }^{(100-104)}$. Findings are again inconsistent. Some studies showed significant effects of lifestyle interventions ${ }^{(100,103)}$ on psychological outcomes, although given their complexity it is difficult to determine whether FV contributed to the psychological changes. Other studies reported null findings ${ }^{(104)}$ or heterogeneous results ${ }^{(101,102)}$ on subscales of the outcome measurement used.

Although some experimental studies do support a positive effect of increased FV intake on psychological health, overall, the number of studies is limited and results are largely inconsistent. Possible reasons for this will be discussed in the following sections.

\section{Possible explanations for inconsistent findings and methodological considerations}

\section{Design of studies on fruit and vegetables and psychological well-being}

It is possible that various study design issues have contributed towards the conflicting results on the role of FV and psychological well-being to date. First, given that the majority of research is observational, it is possible that some studies have been subjected to residual confounding. Although most studies have adjusted for potential confounders, some have not reported any adjustments. Furthermore, there are also inconsistencies in the variables accounted for between studies with some studies not adjusting for factors that could justifiably mediate the relationship between FV intake and psychological well-being such as BMI, physical activity, education level, stressful life events or other dietary factors. An FV-rich diet could be indicative of a healthy lifestyle in general and thus other factors, if not controlled for, could contribute to positive relationships. Secondly, it is important to note that the observational nature of such studies means it is difficult to derive firm conclusions as causality cannot be assumed. For example, some of the significant associations detected in the 
observational studies mentioned throughout this review could in fact be as a result of individual's with better psychological health seeking more health-promoting behaviours including increased consumption of FV and vice versa ${ }^{(105)}$. In line with this, some studies ${ }^{(63,106)}$ have indicated that negative emotions such as stress are associated with an increased consumption of high-fat, energy dense foods and decreased intakes of FV. As such, it is vital that the results from observational studies in this area are considered within the context of the complex interrelationship that exists between food consumption and psychological health. For example, depressed mood is associated with numerous behavioural and physiological responses, such as changes in appetite, sleeping patterns, motivation/energy levels and body-image perceptions, all of which have the potential to influence food choice and consumption ${ }^{(50,67,77,107)}$. Furthermore, depression has been linked with lower socioeconomic status, which in turn has been shown to be related to lower FV consumption ${ }^{(48)}$. Hence, it is not possible to preclude reverse, bidirectional or even multidirectional relationships from such studies and therefore well-designed randomised controlled trials are required to investigate these results further.

Furthermore, studies conducted to date have varied considerably with regard to study populations, and overall sample sizes. For example, observational study sizes have ranged from as few as eighteen ${ }^{(108)}$, to as many as 296121 participants $^{(28)}$, while experimental studies have had as few as twelve participants ${ }^{(90)}$ and as many as $1566^{(102)}$. Thus, it may be the case that some of the small samples were insufficiently powered to detect any association or effect between FV and psychological well-being, and this may serve to explain some of the inconsistency in findings to date. In addition, while a number of studies were conducted in the general population, some examined specific subgroups of the population including elderly people ${ }^{(70)}$ and employees ${ }^{(56,68)}$. As well as possibly contributing towards the conflicting findings discussed, these studies may be limited in terms of their generalisability to wider populations.

Finally, there are evident methodological flaws in some of the experimental studies, including issues such as inadequate control, randomisation and blinding. Owing to these design flaws, research on the area of FV and psychological health thus far should be interpreted with caution. To enhance understanding, future research should employ appropriate and powerful research designs.

\section{Assessment of psychological well-being}

Given the subjective nature of psychological well-being, its measurement is mostly reliant on self-reporting of experiences. Another potential reason for the conflicting findings on FV and psychological well-being to date is the substantial variation in tools used by studies to measure psychological outcomes. Table 3 provides an overview of the different types of self-report measures that have been selected to measure the primary psychological outcomes examined so far in relation to FV.
As illustrated, measurement has varied not only in terms of the tool used, but also with regard to details such as the number of questionnaire items and the language. As well as potentially influencing findings in studies, this makes study comparison difficult. Furthermore, the recall periods specified in psychological measurements within existing studies are diverse. For example, studies have asked respondents to recall experiences/symptoms over the past year ${ }^{(47,74)}, 3$ months $^{(109)}$, month $^{(53)}$, week ${ }^{(20,63)}$, day ${ }^{(60)}$ or recently ${ }^{(78)}$, while some have not reported the recall period ${ }^{(48,76,77)}$. Recall period can influence an individual's interpretation of and response to a question, and hence can impact upon the reliability and validity of the measure ${ }^{(110)}$. For instance, people may have difficulty recalling and generalising symptoms or feelings over a long period of time, due to contrasting experiences and the tendency to prioritise their current psychological state ${ }^{(111)}$. Equally, it has also been suggested that shorter recall periods have the potential to over or underestimate as a result of shortterm fluctuations in psychological state ${ }^{(112)}$. Thus, it may be the case that current findings have been affected by the specifics of outcome tools selected.

Although the majority of existing studies have employed validated measures, some have used single/ multiple item non-validated self-report measures of psychological health ${ }^{(74,97)}$, which could have impacted upon reported findings. It is possible that such methods may not be detailed or sensitive enough to assess psychological outcomes accurately or to detect change in outcomes. Notably, several questionnaires utilised to date have been designed primarily to screen the general population for the absence or presence of psychological disorders or to assess the severity of symptoms within clinical samples. This could be problematic in terms of detecting low levels of psychological symptoms, or indeed change or improvements in psychological wellbeing within normal populations. If experimental research is to explore FV consumption and psychological well-being further within the general population, then there is perhaps a need for the development and validation of tools, which are sensitive enough to detect change in psychological well-being among such individuals.

Furthermore, it is evident that existing studies have predominately examined the association or effect of FV on negative aspects of psychological health (e.g. depression and anxiety). It may be useful for future research to place equal emphasis on the presence of positive psychological well-being (e.g. vitality, happiness and life satisfaction), which could prove more effective at detecting lower levels of, or change in, psychological symptomology in general populations. Arguably, this approach would be closer aligned to the wider concept of health advocated by the WHO, which highlights the importance of complete mental well-being and not merely the absence of disease ${ }^{(113)}$.

In addition, it is possible that other common factors related to the use of self-report measures may have attributed to the conflicting findings, such as social desirability bias. Research has suggested that participants are 
Table 3. Summary of outcome measurements used in existing studies examining fruit and vegetables and psychological well-being

\begin{tabular}{|c|c|c|c|c|}
\hline Example Ref & Measure & Variations used & Target population & Purpose \\
\hline & $\begin{array}{l}\text { General mental } \\
\text { health/well-being }\end{array}$ & & & \\
\hline (67) & $\mathrm{GHQ}$ & Twelve/twenty-eight/thirty items & General & Screens for minor psychiatric disorders \\
\hline (52) & SF-36 & Eight/twelve/thirty-six items & General & $\begin{array}{l}\text { Measures functional health } \\
\text { (mental and physical) }\end{array}$ \\
\hline (59) & WEMWBS & - & General & Assesses positive mental health/well-being \\
\hline (75) & CDC HDM & - & General & $\begin{array}{l}\text { Measures population health related } \\
\text { quality of life }\end{array}$ \\
\hline (109) & Self-report item $/ \mathrm{s}^{*}$ & - & - & - \\
\hline (20) & $\begin{array}{l}\text { Depression } \\
\text { CES-D }\end{array}$ & $\begin{array}{l}\text { Seven/ten/twenty items and } \\
\text { French version }\end{array}$ & General & $\begin{array}{l}\text { Screens for depression/measures } \\
\text { depressive symptomology }\end{array}$ \\
\hline (62) & GDS & $\begin{array}{l}\text { Short form/thirty items; Chinese, } \\
\text { Japanese and Greek versions }\end{array}$ & Elderly & Screens for depression \\
\hline (49) & $\mathrm{BDI}$ & $\begin{array}{l}\text { Modified version and } \\
\text { thirteen items }\end{array}$ & General/clinical & $\begin{array}{l}\text { Screens for and assesses severity } \\
\text { of depression }\end{array}$ \\
\hline (99) & DASS-42 & - & General/clinical & $\begin{array}{l}\text { Measures severity of depression, } \\
\text { anxiety, stress }\end{array}$ \\
\hline (69) & $\mathrm{BSI}$ & Twelve items & General/clinical & Measures PD and psychiatric disorders \\
\hline (28) & CIDI-SF & - & General/clinical & Screens for mental disorders \\
\hline (84) & Self-report item $/ \mathrm{s}^{*}$ & - & - & - \\
\hline (96) & $\begin{array}{l}\text { General mood } \\
\text { POMS }\end{array}$ & $\begin{array}{l}\text { Sixty-five/thirty-seven items; } \\
\text { anger and depression } \\
\text { subscales }\end{array}$ & $\begin{array}{l}\text { General/psychiatric } \\
\text { outpatients }\end{array}$ & $\begin{array}{l}\text { Measures transient, fluctuating, } \\
\text { active mood states }\end{array}$ \\
\hline (96) & BL-VAS & - & General/clinical & Measures subjective feelings \\
\hline (60) & Daily diaries* & - & - & Measures positive and negative affect \\
\hline (79) & SHS & - & - & Measures global subjective happiness \\
\hline (99) & $\begin{array}{l}\text { Anxiety } \\
\text { DASS-42 }\end{array}$ & -7 & General/clinical & $\begin{array}{l}\text { Measures severity of depression, } \\
\text { anxiety, stress }\end{array}$ \\
\hline (55) & STAI & Twenty items (Greek version) & General/clinical & Measures state and trait anxiety \\
\hline (69) & $\mathrm{BSI}$ & Twelve items & General/clinical & Measures PD and psychiatric disorders \\
\hline (58) & $\begin{array}{l}\text { Stress } \\
\text { PSS }\end{array}$ & $\begin{array}{l}\text { Fourteen items/ } \\
\text { Spanish version }\end{array}$ & General & Measures perception of stress \\
\hline (65) & $\begin{array}{l}\text { Stress scale } \\
\text { (eleven items) }\end{array}$ & - & - & - \\
\hline (28) & $\begin{array}{l}\text { Psychological distress } \\
\text { Kessler K6 measure }\end{array}$ & - & General & $\begin{array}{l}\text { Measures non-specific psychological } \\
\text { distress }\end{array}$ \\
\hline (78) & Self-report items ${ }^{*}$ & - & - & - \\
\hline (81) & $\begin{array}{l}\text { Life satisfaction } \\
\text { Self-report item }\end{array}$ & - & - & - \\
\hline
\end{tabular}

GHQ, General Health Questionnaire; SF-36, Medical Outcomes Study 36-item Short-Form Health Survey; WEMWBS, The Warwick-Edinburgh Mental Well-being Scale; CDC HDM, Centers for Disease Control and Prevention Healthy Days Measure; CES-D, Center for Epidemiological Studies Depression Scale;

GDS, Geriatric Depression Scale; BDI, Beck Depression Inventory; DASS-42, Depression Anxiety and Stress Scales 42-items; BSI, Brief Symptom Inventory,

CIDI-SF, Composite International Diagnostic Interview Short Form; POMS, Profile of Mood States, BL-VAS, Bond-Lader Visual Analogue Scales; SHS, Subjective Happiness Scale; STAI, State-Trait Anxiety Inventory; PSS; Perceived Stress Scale; PD, psychological distress.

${ }^{*}$ Measurement tool not validated/validation status unknown.

more likely to over report desirable behaviours when being asked to report on sensitive topics such as levels of $\mathrm{PD}^{(114)}$. For this reason, it may be useful for future research to take account of, discuss and control for the potential impact of social desirability bias on the validity of study results, for example through the use of a social desirability scale ${ }^{(114)}$. Furthermore, given the quantity of items within some psychological selfreport tools, it is possible that multiple comparisons could have led to type one errors, i.e. the identification of false-positive relationships. This could act as a further explanation for the discrepant findings between certain aspects of psychological well-being between the studies mentioned in this review.

In summary, future studies should use well-validated, widely used measures to assess specific aspects of psychological well-being in order to allow for easier comparison between studies in this field. 


\section{Assessment of fruit and vegetable intake}

Similarly, the methods used to measure FV intake are diverse among observational studies, which may have contributed towards the conflicting findings. The most frequently used method of measuring $\mathrm{FV}$ intake in studies to date has been the FFQ, although some have used diet histories ${ }^{(68,72,109)}, 24-\mathrm{h}$ recalls ${ }^{(108)}$ and diet quality scores (which incorporated FV) ${ }^{(52)}$, as well as single items on FV consumption ${ }^{(47,64,78,115)}$. Although FFQ can be a cost-effective means of collecting frequency of dietary intake data from large samples, they are often limited in terms of how much detail they can provide on the quantities of foods consumed ${ }^{(116)}$. As such, some studies that have looked at FV in relation to psychological health have used FFQ to collect information on frequency of FV consumption, but not on amounts consumed $^{(48,57,58)}$. Others have asked participants to report their frequency of $\mathrm{FV}$ intake based on average or medium servings of $\mathrm{FV}^{(20,51,63,76)}$. Inevitably, this may have contributed towards the heterogeneous findings. Moreover, a lack of detail on the portions of FV consumed at each time point makes it difficult to determine the actual amount of FV eaten, and hence less comprehensive conclusions can be made about associations between FV intake and psychological wellbeing. Future studies may benefit from more sensitive measures of FV intake, which can identify individuals who eat lesser and greater amounts. In addition, FFQ also rely on an individual's ability to accurately estimate and calculate their intake, which can be a challenging task, particularly for certain population groups including the elderly. Naturally, this may have impacted upon FV estimation in these studies ${ }^{(116)}$.

Similar to the outcome measures, varying recall periods of FV consumption have been assessed. These ranged from FV intake within the past day ${ }^{(115)}$, to intake over the past year ${ }^{(20,109)}$. The former option may increase the risk of random error and may not accurately reflect habitual intake of FV. Furthermore, in some cases, tools used to measure FV intake were not validated, or validation was not reported $^{(48,55,58,63,70,77)}$. Such variability may have impacted upon the results of these studies, and also makes between-study comparisons difficult. Caution is also necessary when interpreting the results from existing observational studies, as individuals may have over or under-reported their intake of FV based on factors such as social desirability biases ${ }^{(117)}$.

Future observational research on FV and psychological health should endeavour to use validated, detailed measures of FV intake with increased data on the types and quantities of FV consumed. This could provide invaluable information with regard to the amount of FV which is associated with psychological outcomes, and could enhance understanding of the area.

\section{Conclusions and future directions}

Despite indication of a role for FV in promoting psychological well-being, evidence to date can be summarised as largely inconclusive. The conflicting results may be partly due to methodological limitations and study design variations as highlighted throughout this review. A number of key inconsistencies were identified including sample sizes, populations examined, choice of outcome and exposure assessment tools, factors chosen as potential confounders and design issues with regard to experimental studies. These factors should be taken into consideration to improve the credibility of future evidence. The review also highlighted a dearth of longitudinal studies on the topic of FV and psychological health, and thus large-scale prospective studies should be considered a priority. Similarly, well-designed randomised controlled trials that focus specifically on FV intake and psychological well-being are required to replicate findings from observational studies, and to assist in establishing the issue of cause and effect. This work has also emphasised the need for the adoption of a more uniform approach, particularly with regard to the measurement of psychological well-being and FV intake. In addition, given that biological mechanisms surrounding FV consumption and psychological well-being are currently speculative, more exploratory work is required to clarify these potential actions further. Finally, while the current review provides a useful synopsis of existing research on FV and psychological well-being, there is perhaps a need for a more exhaustive synthesis of studies in the form of a systematic review.

\section{Acknowledgements}

None.

\section{Financial support}

The principal author is in receipt of a Centre of Excellence for Public Health NI funded PhD scholarship. The Centre of Excellence for Public Health NI had no role in the design, analysis or writing of this article.

\section{Conflicts of interest}

None.

\section{Authorship}

C. R. conducted the literature search and wrote the original draft of the manuscript. J. V. W. and M. C. M. provided guidance on the outline of the review, and critically reviewed drafts of the manuscript prior to submission.

\section{References}

1. Prince M, Patel V, Saxena S et al. (2007) No health without mental health. Lancet 370, 859-877.

2. Wittchen HU, Jacobi F, Rehm J et al. (2011) The size and burden of mental disorders and other disorders of the brain in Europe 2010. Eur Neuropsychopharmacol 21, 655-679. 
3. World Health Organization (2008) The Global Burden of Disease: 2004 Update. Geneva: WHO.

4. Anderson P, Jané-Llopis E \& Hosman C (2011) Reducing the silent burden of impaired mental health. Health Promot Int 26, i4-i9.

5. Russ TC, Stamatakis E, Hamer M et al. (2012) Association between psychological distress and mortality: individual participant pooled analysis of 10 prospective cohort studies. BMJ 345, e4933.

6. Gustavsson A, Svensson M, Jacobi F et al. (2010) Cost of disorders of the brain in Europe 2010. Eur Neuropsychopharmacol 21, 718-779.

7. Windle G, Hughes D, Linck P et al. (2010) Is exercise effective in promoting mental well-being in older age? A systematic review. Aging Ment Health 14, 652-669.

8. Schuch FB, Vasconcelos-Moreno MP \& Fleck MP (2011) The impact of exercise on quality of life within exercise and depression trials: a systematic review. Ment Health Phys Act 4, 43-48.

9. Rao TSS, Asha MR, Ramesh BN et al. (2008) Understanding nutrition, depression and mental illnesses. Indian J Psychiatry 50, 77-82.

10. Coppen A \& Bolander-Gouaille C (2005) Treatment of depression: time to consider folic acid and vitamin B12. J Psychopharmacol 19, 59-65.

11. Jacobs DR, Gross MD \& Tapsell LC (2009) Food synergy: an operational concept for understanding nutrition. $\mathrm{Am} \mathrm{J}$ Clin Nutr 89, 1543S-1548S.

12. World Health Organization (2003) Diet, Nutrition and the Prevention of Chronic Diseases. Joint WHO/FAO Expert Consultation. WHO Technical Report Series no. 916. Geneva: WHO.

13. He FJ, Nowson CA, Lucas M et al. (2007) Increased consumption of fruit and vegetables is related to a reduced risk of coronary heart disease: meta-analysis of cohort studies. J Hum Hypertens 21, 717-728.

14. Soerjomataram I, Oomen D, Lemmens $\mathrm{V}$ et al. (2010) Increased consumption of fruit and vegetables and future cancer incidence in selected European countries. Eur J Cancer 46, 2563-2580.

15. Appleton KM, Rogers PJ \& Ness AR (2010) Updated systematic review and meta-analysis of the effects of $n-3$ long-chain polyunsaturated fatty acids on depressed mood. Am J Clin Nutr 91, 757-770.

16. Anglin RES, Samaan Z, Walter SD et al. (2013) Vitamin D deficiency and depression in adults: systematic review and meta-analysis. Br J Psychiatry 202, 100-107.

17. Jones EK, Sünram-Lea SI \& Wesnes KA (2012) Acute ingestion of different macronutrients differentially enhances aspects of memory and attention in healthy young adults. Biol Psychol 89, 477-486.

18. Pasman WJ, Blokdijk VM, Bertina FM et al. (2003) Effect of two breakfasts, different in carbohydrate composition, on hunger and satiety and mood in healthy men. Int J Obes Relat Metab Disord 27, 663-668.

19. Best T, Kemps E \& Bryan J (2011) Perceived changes in well-being following polysaccharide intake in middle-aged adults. Appl Res Qual Life 7, 183-192.

20. Akbaraly TN, Brunner EJ, Ferrie JE et al. (2009) Dietary pattern and depressive symptoms in middle age. Br J Psychiatry 195, 408-413.

21. Stough C, Scholey A, Lloyd J et al. (2011) The effect of 90 day administration of a high dose vitamin B-complex on work stress. Hum Psychopharmacol 26, 470-476.

22. Jacka FN, Maes M, Pasco JA et al. (2012) Nutrient intakes and the common mental disorders in women. $J$ Affect Disord 141, 79-85.
23. Sánchez-Villegas A, Henríquez $\mathrm{P}$, Bes-Rastrollo $\mathrm{M}$ et al. (2006) Mediterranean diet and depression. Public Health Nutr 9, 1104-1109.

24. Sanhueza C, Ryan L \& Foxcroft DR (2013) Diet and the risk of unipolar depression in adults: systematic review of cohort studies. J Hum Nutr Diet 26, 56-70.

25. Long SJ \& Benton D (2013) Effects of vitamin and mineral supplementation on stress, mild psychiatric symptoms and mood in nonclinical samples: a meta-analysis. Psychosom Med 75, 144-153.

26. Morgan AJ \& Jorm AF (2008) Self-help interventions for depressive disorders and depressive symptoms: a systematic review. Ann Gen Psychiatry 7, 13.

27. Murakami K \& Sasaki S (2010) Dietary intake and depressive symptoms: a systematic review of observational studies. Mol Nutr Food Res 54, 471-488.

28. McMartin SE, Jacka FN \& Colman I (2013) The association between fruit and vegetable consumption and mental health disorders: evidence from five waves of a national survey of Canadians. Prev Med 56, 225-230.

29. Payne ME, Steck SE, George RR et al. (2012) Fruit, vegetable, and antioxidant intakes are lower in older adults with depression. J Acad Nutr Diet 112, 2022-2027.

30. Tiemeier H, Hofman A, Kiliaan AJ et al. (2002) Vitamin E and depressive symptoms are not related. The Rotterdam Study. J Affect Disord 72, 79-83.

31. Wightman EL, Haskell CF, Forster JS et al. (2012) Epigallocatechin gallate, cerebral blood flow parameters, cognitive performance and mood in healthy humans: a double-blind, placebo-controlled, crossover investigation. Hum Psychopharmacol 27, 177-186.

32. Briançon S, Boini S, Bertrais S et al. (2011) Long-term antioxidant supplementation has no effect on healthrelated quality of life: the randomized double-blind, placebo-controlled primary prevention SU.VI.MAX trial. Int $J$ Epidemiol 40, 1605-1616.

33. Boehm JK, Williams DR, Rimm EB et al. (2013) Association between optimism and serum antioxidants in the midlife in the United States Study. Psychosom Med 75, 2-10.

34. Brody S (2002) High-dose ascorbic acid increases intercourse frequency and improves mood: a randomized controlled clinical trial. Biol Psychiatry 52, 371-374.

35. Capuron L, Moranis A, Combe N et al. (2009) Vitamin E status and quality of life in the elderly: influence of inflammatory processes. Br J Nutr 102, 1390-1394.

36. German L, Kahana C, Rosenfeld V et al. (2011) Depressive symptoms are associated with food insufficiency and nutritional deficiencies in poor community-dwelling elderly people. J Nutr Health Aging 15, 3-8.

37. Gomez-Pinilla F \& Nguyen TT (2012) Natural mood foods: the actions of polyphenols against psychiatric and cognitive disorders. Nutr Neurosci 15, 127-133.

38. Zhu WL, Shi HS, Wei YM et al. (2012) Green tea polyphenols produce antidepressant-like effects in adult mice. Pharmacol Res 65, 74-80.

39. Brown AL, Lane J, Coverly J et al. (2009) Effects of dietary supplementation with the green tea polyphenol epigallocatechin-3-gallate on insulin resistance and associated metabolic risk factors: randomized controlled trial. Br J Nutr 101, 886-894.

40. Pase MP, Scholey AB, Pipingas A et al. (2013) Cocoa polyphenols enhance positive mood states but not cognitive performance: a randomized, placebo-controlled trial. J Psychopharmacol 27, 451-458.

41. Kaplan BJ, Crawford SG, Field CJ et al. (2007) Vitamins, minerals and mood. Psychol Bull 133, 747-760. 
42. Shariatpanaahi MV, Shariatpanaahi ZV, Moshtaaghi M et al. (2013) The relationship between depression and serum ferritin level. Eur J Clin Nutr 61, 532-535.

43. Jung KI, Ock SM, Chung JH et al. (2010) Associations of serum $\mathrm{Ca}$ and $\mathrm{Mg}$ levels with mental health in adult women without psychiatric disorders. Biol Trace Elem Res 133, 153-161.

44. Molteni R, Barnard RJ, Ying Z et al. (2002) A high-fat, refined sugar diet reduces hippocampal brain-derived neurotrophic factor, neuronal plasticity, and learning. Neuroscience 112, 803-814.

45. Lattimore $\mathrm{P}$, Walton J, Bartlett $\mathrm{S}$ et al. (2010) Regular consumption of a cereal breakfast. Effects on mood and body image satisfaction in adult non-obese women. Appetite 55, $512-521$.

46. Hayes JF, D'Anci KE \& Kanarek RB (2011) Foods that are perceived as healthy or unhealthy differentially alter young women's state body image. Appetite 57, 384-387.

47. Adams TB \& Colner W (2008) The association of multiple risk factors with fruit and vegetable intake among a nationwide sample of college students. $\mathrm{J}$ Am Coll Health 56, 455-461.

48. Appleton KM, Woodside JV, Yarnell JWG et al. (2007) Depressed mood and dietary fish intake: direct relationship or indirect relationship as a result of diet and lifestyle? $J$ Affect Disord 104, 217-223.

49. Allgöwer A, Wardle J \& Steptoe A (2001) Depressive symptoms, social support, and personal health behaviors in young men and women. Health Psychol 20, 223-227.

50. Fulkerson JA, Sherwood NE, Perry CL et al. (2004) Depressive symptoms and adolescent eating and health behaviors: a multifaceted view in a population-based sample. Prev Med 38, 865-875.

51. Myint PK, Welch AA, Bingham SA et al. (2007) Fruit and vegetable consumption and self-reported functional health in men and women in the European Prospective Investigation into Cancer-Norfolk (EPIC-Norfolk): a population-based cross-sectional study. Public Health Nutr 10, $34-41$.

52. Blank L, Grimsley M, Goyder E et al. (2007) Community-based lifestyle interventions: changing behaviour and improving health. J Public Health 29, 236-245.

53. McGuire LC, Strine TW, Okoro CA et al. (2007) Modifiable characteristics of a healthy lifestyle in U.S. older adults with or without frequent mental distress: 2003 Behavioral Risk Factor Surveillance System. Am J Geriatr Psychiatry 15, 754-761.

54. Kiviniemi MT, Orom H \& Giovino GA (2011) Race/ethnicity, psychological distress, and fruit/vegetable consumption: the nature of the distress-behavior relation differs by race/ethnicity. Appetite 56, 737-740.

55. Yannakoulia M, Panagiotakos DB, Pitsavos C et al. (2008) Eating habits in relations to anxiety symptoms among apparently healthy adults. A pattern analysis from the ATTICA Study. Appetite 51, 519-525.

56. Pronk NP, Lowry M, Thomas E et al. (2011) Adherence to optimal lifestyle behaviors is related to emotional health indicators among employees. Popul Health Manag 14, 59-67.

57. Liu C, Xie B, Chou CP et al. (2007) Perceived stress, depression and food consumption frequency in the college students of China seven cities. Physiol Behav 92, 748-754.

58. Mikolajczyk RT, El Ansari W \& Maxwell AE (2009) Food consumption frequency and perceived stress and depressive symptoms among students in three European countries. Nutr $J \mathbf{8}, 31$.
59. Blanchflower DG, Oswald AJ \& Stewart-Brown S (2013) Is psychological well-being linked to the consumption of fruit and vegetables? Soc Indic Res (Epublication ahead of print version).

60. White BA, Horwath CC \& Conner TS (2013) Many apples a day keep the blues away - daily experiences of negative and positive affect and food consumption in young adults. $\mathrm{Br} J$ Health Psychol (Epublication ahead of print version)

61. Hintikka J, Tolmunen T, Honkalampi K et al. (2005) Daily tea drinking is associated with a low level of depressive symptoms in the Finnish general population. Eur $J$ Epidemiol 20, 359-363.

62. Woo J, Lynn H, Lau WY et al. (2006) Nutrient intake and psychological health in an elderly Chinese population. Int J Geriatr Psychiatry 21, 1036-1043.

63. Konttinen H, Männistö S, Sarlio-Lähteenkorva S et al. (2010) Emotional eating, depressive symptoms and selfreported food consumption. A population-based study. Appetite 54, 473-479.

64. Verger P, Lions C \& Ventelou B (2009) Is depression associated with health risk-related behaviour clusters in adults? Eur J Public Health 19, 618-624.

65. George GC, Milani TJ, Hanss-Nuss H et al. (2005) Compliance with dietary guidelines and relationship to psychosocial factors in low-income women in late postpartum. $J$ A Diet Assoc 105, 916-926.

66. Kuczmarski MF, Cremer Sees A, Hotchkiss L et al. (2010) Higher Healthy Eating Index-2005 Scores associated with reduced symptoms of depression in an urban population: findings from the Healthy Aging in Neighborhoods of Diversity Across the Life Span (HANDLS) Study. $J A$ Diet Assoc 110, 383-389.

67. Jacka FN, Pasco JA, Mykletun A et al. (2010) Association of Western and traditional diets with depression and anxiety in women. Am J Psychiatry 167, 305-311.

68. Nanri A, Kimura Y, Matsushita Y et al. (2010) Dietary patterns and depressive symptoms among Japanese men and women. Eur J Clin Nutr 64, 832-839.

69. Bowen DJ, Alfano CM, McGregor BA et al. (2004) The relationship between perceived risk, affect, and health behaviors. Cancer Detect Prev 28, 409-417.

70. Mamplekou E, Bountziouka V, Psaltopoulou $\mathrm{T}$ et al. (2010) Urban environment, physical inactivity and unhealthy dietary habits correlate to depression among elderly living in eastern Mediterranean islands: the MEDIS (MEDiterranean ISlands elderly) study. $J$ Nutr Health Aging 14, 449-455.

71. Wardle J, Haase AM, Steptoe A et al. (2004) Gender differences in food choice: the contribution of health beliefs and dieting. Ann Behav Med 27, 107-116.

72. Niu K, Guo H, Kakizaki M et al. (2013) A tomato-rich diet is related to depressive symptoms among an elderly population aged 70 years and over: a population-based, cross-sectional analysis. J Affect Disord 144, 165-170.

73. O'Connor DB, Conner M, Jones F et al. (2009) Exploring the benefits of conscientiousness: an investigation of the role of daily stressors and health behaviors. Ann Behav Med 37, 184-196.

74. Eckert KA, Wilkinson D, Taylor AW et al. (2006) A population view of mental illness in South Australia: boarder issues than location. Rural Remote Health 6, 541.

75. Froshaug DB, Dickinson LM, Fernald DH et al. (2009) Personal health behaviors are associated with physical and mental unhealthy days: a prescription for health (P4H) Practice-based Research Networks Study. $J$ Am Board Fam Med 22, 368-374. 
76. Muñoz MA, Fito M, Marrugat J et al. (2009) Adherence to the Mediterranean diet is associated with better mental and physical health. Br J Nutr 101, 1821-1827.

77. Sarlio-Lähteenkorva S, Lahelma E \& Roos E (2004) Mental health and food habits among employed women and men. Appetite 42, 151-156.

78. Cockerham WC, Hinote BP \& Abbott P (2006) Psychological distress, gender, and health lifestyles in Belarus, Kazakhstan, Russia, and Ukraine. Soc Sci Med 63, 2381-2394.

79. Piqueras J, Kuhne W, Vera-Villarroel P et al. (2011) Happiness and health behaviours in Chilean college students: a cross-sectional survey. BMC Public Health 11, 443 .

80. Grant N, Wardle J \& Steptoe A (2009) The relationship between life satisfaction and health behavior: a crosssectional analysis of young adults. Int J Behav Med 16, 259-268.

81. Lengyel CO, Tate RB \& Obirek Blatz AK (2009) The relationships between food group consumption, selfrated health, and life satisfaction of community-dwelling Canadian older men: the Manitoba follow-up study. $J$ Nutr Elder 28, 158-173.

82. Kelloniemi H, Ek E \& Laitinen J (2005) Optimism, dietary habits, body mass index and smoking among young Finnish adults. Appetite 45, 169-176.

83. Elfhag K, Tholin S \& Rasmussen F (2008) Consumption of fruit, vegetables, sweets and soft drinks are associated with psychological dimensions of eating behaviour in parents and their 12-year-old children. Public Health Nutr 11, 914-923.

84. Sánchez-Villegas A, Delgado-Rodríguez M, Alonso A et al. (2009) Association of the Mediterranean dietary pattern with the incidence of depression. Arch Gen Psychiatry 66, 1090-1098.

85. Le Port A, Gueguen A, Kesse-Guyot E et al. (2012) Association between dietary patterns and depressive symptoms over time: a 10-year follow-up study of the GAZEL cohort. PLoS ONE 7, e51593.

86. Tsai AC, Chang T-L \& Chi S-H (2011) Frequent consumption of vegetables predicts lower risk of depression in older Taiwanese - results of a prospective populationbased study. Public Health Nutr 15, 1087-1092.

87. Jacka FN, Kremer PJ, Berk M et al. (2011) A prospective study of diet quality and mental health in adolescents. $P L O S O N E$ 6, e24805.

88. Jacka FN, Rothon C, Taylor S et al. (2012) Diet quality and mental health problems in adolescents from East London: a prospective study. Soc Psychiatry Psychiatr Epidemiol 48, 1297-1306.

89. Giltay EJ, Gelenijnse JM, Zitman FG et al. (2007) Lifestyle and dietary correlates of dispositional optimism in men: the Zutphen Elderly Study. J Psychosom Res 63, 483-490.

90. Krikorian R, Nash T, Shidler MD et al. (2010) Concord grape juice supplementation improves memory function in older adults with mild cognitive impairment. $\mathrm{Br} J \mathrm{Nutr}$ 103, 730-734.

91. Krikorian R, Shidler MD, Nash TA et al. (2010) Blueberry supplementation improves memory in older adults. $J$ Agric Food Chem 58, 3996-4000.

92. Plaisted CS, Lin P-H, Ard JD et al. (1998) The effects of dietary patterns on quality of life: a substudy of the Dietary Approaches to Stop Hypertension Trial. $J$ Am Diet Assoc 99, S84-S89.

93. Young DR, Coughlin J, Jerome GJ et al. (2010) Effects of the PREMIER interventions on health-related quality of life. Ann Behav Med 40, 302-312.
94. Steptoe A, Perkins-Porras L, Hilton S et al. (2004) Quality of life and self-rated health in relation to changes in fruit and vegetables intake and in plasma vitamins $C$ and $E$ in a randomised trial of behavioural and nutritional education counselling. Br J Nutr 92, 177-184.

95. Torres SJ \& Nowson CA (2012) A moderate-sodium DASH-type diet improves mood in postmenopausal women. Nutr 28, 896-900.

96. McMillan L, Owen L, Kras M et al. (2011) Behavioural effects of a 10-day Mediterranean diet. Results from a pilot study evaluating mood and cognitive performance. Appetite 56, 143-147.

97. Crews WD, Harrison DW, Griffin ML et al. (2005) A double-blinded, placebo-controlled, randomized trial of the neuropsychologic efficacy of cranberry juice in a sample of cognitively intact older adults: pilot study findings. $J$ Altern Complement Med 2, 305-309.

98. Wardle J, Rogers P, Judd P et al. (2000) Randomised trial of the effects of cholesterol-lowering dietary treatment on psychological function. Am J Med 108, 547-553.

99. Beezhold BL \& Johnston CS (2012) Restriction of meat, fish, and poultry in omnivores improves mood: a pilot randomized controlled trial. Nutr $J \mathbf{1 1}, 9$.

100. Block G, Sternfeld B, Block CH et al. (2008) Development of Alive! (A Lifestyle Intervention Via Email), and its effect on health-related quality of life, presenteeism, and other behavioral outcomes: randomized controlled trial. $J$ Med Internet Res 10, e43.

101. Cooley K, Szczurko O, Perri D et al. (2009) Naturopathic care for anxiety: a randomized controlled trial ISRCTN78958974. PloS ONE 4, e6628.

102. Zhou B, Chen K, Yu Y et al. (2010) Individualized health intervention: behavioral change and quality of life in an older rural Chinese population. Educ Gerontol 36, 919-939.

103. Surkan PJ, Gottlieb BR, McCormick MC et al. (2012) Impact of a health promotion intervention on maternal depressive symptoms at 15 months postpartum. Matern Child Health J 16, 139-148.

104. Strijk JE, Proper KI, van der Beek AJ et al. (2012) A worksite vitality intervention to improve older workers' lifestyle and vitality-related outcomes: results of a randomised controlled trial. J Epidemiol Commun Health 66, 1071-1078.

105. Zellner D, Loaiza S, Gonzalez Z et al. (2006) Food selection changes under stress. Physiol Behav 87, 789-793.

106. Oliver G \& Wardle J (1999) Perceived effects of stress on food choice. Physiol Behav 66, 511-515.

107. Macht M (2008) How emotions affect eating: a five-way model. Appetite 50, 1-11.

108. Fowles ER, Murphey C, Ruiz RJ et al. (2011) Exploring relationships among psychosocial status, dietary quality, and measures of placental development during the first trimester in low-income women. Biol Rev Nurs 13, 70-79.

109. Hakkararainen R, Partonen T, Haukka J et al. (2004) Food and nutrient intake in relation to mental wellbeing. J Nur 3, 14.

110. Stull DE, Leidy NK, Parasuraman B et al. (2009) Optimal recall periods for patient-reported outcomes: challenges and potential solutions. Curr Med Res Opin 25, 929-942.

111. Steptoe A, Dockray S \& Wardle J (2010) Positive affect and psychobiological processes relevant to health. NIH Public Access 77, 1-19. 
112. Norquist JM, Girman C, Fehnel S et al. (2012) Choice of recall period for patient-reported outcome (PRO) measures: criteria for consideration. Qual Life Res 21, 10131020.

113. World Health Organization. (2010) Mental health: strengthening our response. Available at: http://www. who.int/mediacentre/factsheets/fs220/en/.

114. Mortel TF Van De (2008) Faking it: social desirability response bias in self-report research report research. Aust J Adv Nurs 25, 40-48.
115. Mistry R, McCarthy WJ, Yancey AK et al. (2009) Resilience and patterns of health risk behaviors in California adolescents. Prev Med 48, 291-297.

116. Rutishauser IH (2007) Dietary intake measurements. Public Health Nutr 8, 1100-1107.

117. Miller TM, Abdel-Maksoud MF, Crane L et al. (2008) Effects of social approval bias on self-reported fruit and vegetable consumption: a randomized controlled trial. Nutr J 7, 18. 